\title{
Extensão universitária e prática dos agentes comunitários de saúde: acolhimento e aprendizado cidadão
}

\section{University extension and practice of community health workers: welcome and citizen learning}

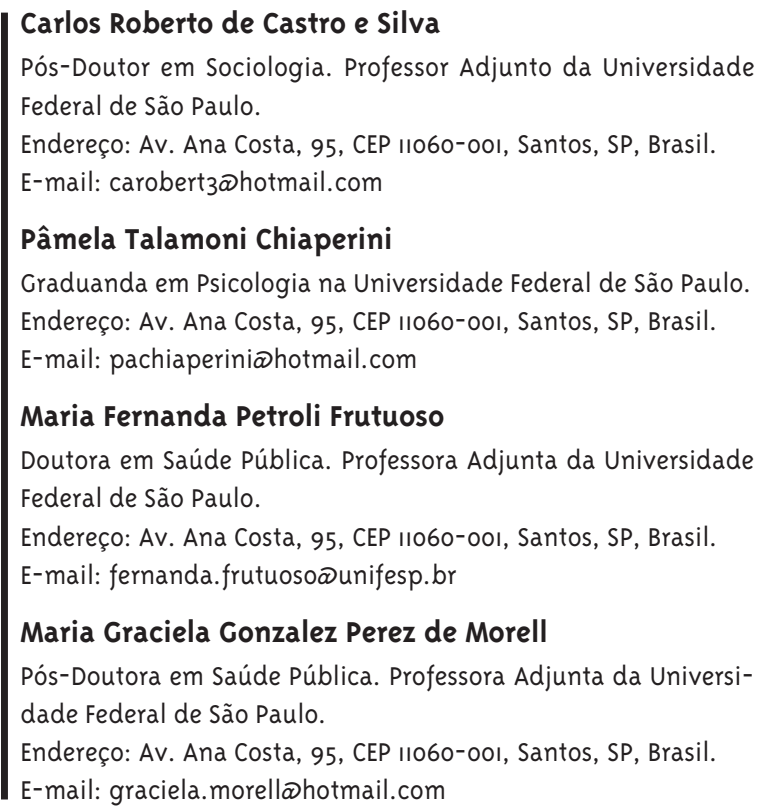

\section{Resumo}

A intervenção interdisciplinar universitária em regiões de alta vulnerabilidade da Baixada Santista, além de contribuir para o fortalecimento do Sistema Único de Saúde (SUS), evidencia o sofrimento enfrentado pelo agente comunitário de saúde (ACS) em seu dia a dia, advindo de solicitações dos munícipes. Estas resultantes da exclusão e violência social em que vivem acrescidas de condições de trabalho insalubres e baixa remuneração. 0 objetivo deste artigo é apresentar a sistematização de uma experiência de intervenção por meio de um projeto de extensão universitária, trazendo elementos que potencializem as ações dos agentes comunitários de saúde da Estratégia Saúde da Família (ESF) na Baixada Santista. Para este estudo qualitativo, foram analisados os diários de campo dos encontros semanais, a partir da percepção de professores e alunos, referentes ao período de agosto de 2010 a junho de 2011. A organização e análise dos dados tiveram como referência a Teoria Fundamentada nos dados. Os resultados indicaram a necessidade de acolhimento de experiências dos ACSs, ampliando a compreensão dos dilemas vividos por estes profissionais e consequentemente dos impasses de implementação do SUS e da ESF. Além disso, o incentivo ao processo de educação continuada baseada em uma práxis que promova os projetos de vida pessoais e profissionais dos ACSs.

Palavras-chave: Estratégia de Saúde da Família; Agentes Comunitários de Saúde; Educação Continuada; Acolhimento; Pesquisa Qualitativa; Extensão Universitária. 


\section{Abstract}

The interdisciplinary intervention by the university in areas of high vulnerability of Santos, besides contributing to the strengthening of the Brazilian National Health System (SUS), highlights the suffering faced by community health agents (CHA) in their routines, coming from requests from citizens. These result from social exclusion and the violence in which they live, as well as unhealthy working conditions and low pay. The purpose of this article is to present an experience of systematic intervention through a university extension project, bringing elements that enhance the actions of community health agents of the Family Health Strategy (FHS) in Santos. For this qualitative study we analyzed the field diaries of weekly meetings, from the perspective of teachers and students, for the period from August 2010 to June 2011. Data's organization and analysis were based on the Grounded Theory. The results indicated the need of gathering the CHA experiences, broadening the understanding of the dilemmas faced by these professionals and consequently the impasses of implementing SUS and the FHS. Moreover, continued education should be encouraged, based upon a praxis able to promote CHA's personal and professional projects.

Keywords: Family Health Estrategy; Community Health Workers; Continued Education; Welcome; Qualitative Research; University Extension.

\section{Introdução}

A Estratégia Saúde da Família (ESF) traz em seu âmago muitas das expectativas de construção de um sistema de saúde mais justo e eficaz, pois favorece maior proximidade das demandas da população e busca novas formas de intervenção calcadas na promoção de saúde e prevenção de doenças. Ao mesmo tempo, evidencia as contradições e deficiências de um sistema de saúde com muitas precariedades, principalmente aquelas advindas de uma lógica mercantilista da saúde e/ou daquelas que privilegiam intervenções de alto custo tecnológico, muitas vezes inacessíveis e ineficazes para a maioria das demandas da população (Ceccim e Merhy, 2009; Pasche e col., 2011).

A prática da ESF promove ações que aproximam sistema/equipes de saúde e as comunidades, por meio de visitas e acompanhamentos nos equipamentos, domicílio e territórios onde os usuários vivem. Tal organização de trabalho e produção de cuidado tem um personagem importante na mediação entre as pessoas em suas comunidades e o sistema de saúde: o agente comunitário de saúde (ACS), profissional este que tem por função a primeira aproximação com as famílias, o acompanhamento e encaminhamentos a tratamentos e/ou cuidados dispensados àquela(s) família(s). Ele se torna um elo fundamental para a eficiência e eficácia da proposta da ESF, pois além de conhecer de perto a comunidade, uma vez que é lá que ele vive - sendo este inclusive, um dos critérios para exercer tal função -, promove a troca de saberes entre as pessoas da comunidade e os profissionais (Nunes e col., 2002; Ferreira e col., 2009; Gomes e col., 2010; Santos e col., 2011).

Desta forma, os ACSs enfrentam as pressões de demandas das mais diversas, desde problemas de relacionamento familiar e outros que envolvem as relações humanas até problemas de ordem social como a miséria e outras formas de violência urbana e seus correlatos como tráfico e uso de drogas. Situações que evidenciam contextos de alta vulnerabilidade, que por sua vez expressam a incipiência das ações do Estado e consequentemente a dificuldade do cumprimento dos preceitos do SUS, principalmente da integralidade, equidade, intersetorialidade e participação social (Jardim e Lancman, 2009; Santos e col., 2010). 
A profissão de ACS, criada em 10 de julho de 2002, pela Lei n.10.507 (Brasil, 2002), tem suas atividades regulamentadas a partir de 2006, pela Lei n. 11.350, que define suas atribuições e determina a conclusão do ensino fundamental e o curso introdutório de formação inicial e continuada, de responsabilidade dos Municípios, como requisitos mínimos para o exercício da profissão (Brasil, 2006).

Concomitantemente, com o objetivo de fortalecer e melhorar a qualidade dos serviços do setor saúde, atendendo às demandas da população, o Ministério da Saúde (MS) em conjunto com o Ministério da Educação (MEC), elaborou o Referencial Curricular Nacional para formação técnica de Agente Comunitário de Saúde, tendo como base a Lei Federal n. 9.394/96 que estabelece as diretrizes e bases da educação nacional (LDB). Assim, estrutura-se o curso de Técnico de Agente Comunitário de Saúde com uma carga horária de 1.200 horas, respeitando a Resolução CNE/CEB n. 04/9916, que institui as Diretrizes Curriculares Nacionais para a Educação Profissional de Nível Técnico, elaborado através de itinerários formativos (Brasil, 2004). Todavia, somente o primeiro módulo deste curso foi ministrado pelas escolas técnicas do SUS e os outros dois ainda não obtiveram financiamento. Situação que fragiliza a luta da categoria por melhores condições de trabalho e qualificação (Lacerda, 2010).

Nesta perspectiva, cabe ponderar que por um lado, atendendo à Portaria 648/o6, a consolidação da ESF está condicionada à existência de profissionais com conhecimentos, habilidades e atitudes adequados a esse novo modelo de atenção que enfatiza o trabalho em equipe, o acolhimento e a humanização. Por outro lado, questiona-se sobre os processos de formação dos ACSs diante das necessidades da comunidade em que vivem e atuam muitas vezes desarticulados do contexto de suas práticas.

Na Baixada Santista, a partir de um dos eixos de ensino de uma universidade pública denominado Trabalho em Saúde, tem-se priorizado situações de aprendizagem em diferentes cenários, incluindo unidades da Estratégia Saúde da Família em regiões de maior vulnerabilidade social na região (Unifesp, 2006). Esta aposta de formação permitiu a aproximação crescente com a equipe da ESF de uma região de alta vulnerabilidade e a percepção de demanda específica dos ACSs que requisitavam um espaço de escuta e de discussão sobre as dificuldades diárias na realização do seu trabalho. Eles diziam: Nós cuidamos dos munícipes e quem cuida de nós? (sic).

Associada à demanda da Secretaria Municipal de Saúde do município, em contrapartida, a Universidade propôs, em 2009, uma ação extensionista visando à criação de um espaço para a escuta e acolhimento das experiências cotidianas do trabalho, ao mesmo tempo o exercício de formas alternativas de qualificação.

Neste contexto, o objetivo geral deste artigo é trazer algumas das principais lições aprendidas com o desenvolvimento de um projeto de extensão universitária baseado na construção de encontros grupais com agentes comunitários de saúde da Estratégia Saúde da Família em unidades situadas nos Morros da Baixada Santista.

\section{Método: a construção de dados a partir da experiência}

Os morros de Vila Progresso e Santa Maria são uma região de alta vulnerabilidade, os quais remontam a ocupações territoriais recentes. 0 primeiro consolidou-se no fim da década de 1970, então habitada principalmente por ex-moradores do morro da Nova Cintra; o segundo, a partir da década de 8o, foi impulsionado por sua vez por ex-moradores também da Nova Cintra e da Vila Progresso. Em 200o, totalizavam aproximadamente 5,1 mil habitantes (Vila Progresso: 350o; Santa Maria: 16oo). A Unidade de Saúde da Família da Vila Progresso que atende os munícipes de ambos os Morros completou quatro anos de existência em 2011, abrigando duas equipes da ESF (compostas cada uma delas por seis ACSs, um técnico de enfermagem, um enfermeiro e dois médicos). Nesta unidade de saúde trabalham 28 funcionários, nos períodos da manhã e tarde.

Foi elaborado um Projeto de Extensão denominado: "A potencialização da capacidade de ação dos Agentes Comunitários dos Morros Santa Maria e Vila Progresso", que buscou promover do ponto de vista psicossocial, um espaço de escuta, acolhimento e elaboração de vivências desencadeadas na atuação do ACS na ESF, além disso, de buscar estratégias para potencializar a capacidade de ação destes pro- 
fissionais. Este projeto começou a ser desenvolvido em agosto de 2009, com a aprovação e subsídios da Pró-Reitoria de extensão (esta concedeu três bolsas para alunos da graduação). Estes bolsistas e alguns estudantes e professores voluntários desenvolveram junto com professores de áreas distintas (Psicologia, Nutrição e Saúde Coletiva, inclusive com as participações pontuais de outras áreas do conhecimento) atividades de planejamento, execução e avaliação. Cabe destacar que esta equipe se reunia sistematicamente para discutir e planejar tais atividades. Estas atividades eram de natureza grupal, realizadas uma vez por semana, com duas horas de duração, por dois anos, em locais da comunidade (salões de igrejas) ou em salas da universidade, conforme o tipo da atividade. Era dispendido um total de 10 horas por semana.

Este trabalho de caráter qualitativo tem seus resultados provenientes da sistematização dos diários de campo dos encontros semanais com os ACSs, referente ao período de agosto de 2010 a junho de 2011, destacando as atividades sobre ervas medicinais e saber popular denominado: "O ACS e a valorização dos saberes populares sobre práticas alternativas de cuidado à saúde: as ervas, trabalho de grupo e muita prosa”. Foram 19 diários realizados por professores e estudantes, descrevendo a experiência e dinâmica vividas nos encontros com os ACSs, organizados em notas descritivas e notas intensivas. Neste momento do projeto, participavam (o7) ACSs, do total inicial de 12 ACSs. Apesar de menos ACSs, foi um momento de maior amadurecimento da proposta de extensão além da intensidade dos encontros, haja vista maior consolidação dos vínculos entre a equipe da universidade e os ACSs.

O planejamento dos encontros semanais, de duas horas cada, com os ACSs cumpriram as seguintes etapas: 1- Levantamento dos saberes sobre os cuidados vivenciados pelos ACSs em suas trajetórias de vida; 2 - Descrição e desenvolvimento das estratégias de cuidados à saúde, que envolviam as diferentes plantas medicinais e temperos (ervas), referentes à vivência dos ACSs na comunidade em que moram e atuam; 3- Aprofundamento do saber trazido pelos ACSs sobre algumas destas estratégias e remédios caseiros (participação de especialistas); 4- Introdução de trabalho com grupos (organização de grupos com pessoas da comunidade, das regiões onde os ACSs atuam, sob a coordenação dos próprios ACSs).

Cabe destacar que cada uma destas etapas, as quais davam contorno para as atividades, eram descritas pelos seguintes tópicos: objetivos (as metas a serem atingidas naquele encontro), estratégias (métodos de abordagem e operacionalização do encontro), habilidades (as competências que buscávamos serem incrementadas).

Do ponto de vista de organização e análise dos dados, fez-se a opção pela Teoria Fundamentada nos Dados. Esta escolha metodológica tinha como principal meta possibilitar a apreensão de uma realidade concreta a partir da dinâmica cotidiana das interações humanas por meio das atividades da ação extensionista. Este tipo de opção surgiu devido à hipótese de que "extrair" da prática cotidiana as formas de interação entre os ACSs e aspectos de seu cotidiano poderia oferecer novos elementos sobre a maneira pela qual, na prática, podemos pensar formas alternativas de acolhimento e escuta, subsidiando ações de educação continuada.

Neste sentido, a opção pelo referencial metodológico da Teoria Fundamentada nos Dados (Grounded Theory-GT) mostrou-se pertinente, pois ela tem em seu fundamento a proposta de construir teorias a partir do trabalho empírico ou de um privilégio do trabalho de campo (Charmaz, 2009). A principal hipótese que baseia a GT é: "A geração da teoria vinda dos dados significa que mais hipóteses e conceitos não somente vêm de dados, mas são sistematicamente trabalhados a partir da relação com os dados durante o curso da pesquisa" (Glaser e Strauss, 1967, p. 6). Pode-se considerar que a teoria é gerada através de três etapas: coleta de dados, codificação e análise. Tais etapas dão-se conjuntamente, pois, para os autores da GT, separá-los impediria a geração da teoria.

Os 19 diários de campo, a principal fonte de dados desta experiência extensionista, foram sistematizados da seguinte forma: 1- Leitura flutuante do material, grifando principais palavras e trechos dos registros, etapa realizada por cada um dos pesquisadores, individualmente; 2- Organização dos trechos destacados em categorias empíricas; 3- Comparação entre estas categorias produzidas individualmente, com discussão e maior consistência para a escolha das categorias predominantes; 4- Reorganização 
destas categorias preliminares em categorias maiores, as quais refletiam com mais consistência os achados; 5- Teorização dos dados que emergiram da análise destas categorias. Cabe reiterar que este trabalho se configura como relato de experiência, por isso não foi submetido a nenhum comitê de ética.

\section{Resultados}

A partir da sistematização das informações trazidas pelos diários sobre as atividades extensionistas, foi possível identificar, em meio às fronteiras porosas e às vezes frágeis deste espaço de suporte psicossocial, pistas sobre alternativas de práticas que potencializem os ACSs atuantes na ESF dos Morros na Baixada Santista, destacando os seguintes aspectos: trajetória de vida dos ACSs e os vínculos comunitários; características e dinâmica das atividades extensionistas e a organização do trabalho dos ACSs.

Os ACSs revelaram um vínculo muito forte com a comunidade e o conhecimento que traziam para o trabalho cotidiano era resultante das tradições de família e do saber adquirido com pessoas de sua convivência comunitária. 0 desenvolvimento das atividades sobre plantas medicinais mostrou que muito do que os ACSs sabiam sobre as plantas e seu poder curativo vinha da transmissão do conhecimento de uma geração para outra, destacando a transmissão de mãe para filhos. Esta atividade revelou um lugar simbólico de potência dos ACSs, pois alimentava sentimentos de pertencimento e uma identidade que encontram um esteio em suas próprias historias de vida (Jariego, 2004):

Nesse grupo disseram que colocaram os ensinamentos sobre ervas que as mães passaram pra estas e que agora muitas das coisas usam com os filhos (Relato de 25.10.10).

As atividades de levantamento de plantas medicinais nos Morros tinham como pressuposto envolver pessoas da comunidade com interesse e/ou conhecimento do assunto. Estas visitas conjuntas da equipe da extensão e dos ACSs evidenciaram os fortes vínculos que os ACSs têm com os munícipes e o conhecimento dos recursos da comunidade. Aspecto que reitera a importância da obrigatoriedade de moradia na comunidade, pois este conhece melhor os problemas que os munícipes vivenciam, facilitando a construção de vínculos de confiança. Nesta perspectiva o ACS expressa uma identidade diferenciada em relação ao restante da equipe de saúde (Ramos, 2007; Lacerda, 2010).

Notamos nas visitas ao território um forte sentimento de comunidade expresso pelo ACS, definido como "um sentimento de pertença que os membros possuem, de que os membros se preocupam uns com os outros e com o grupo, e uma fé partilhada de que as necessidades dos membros serão satisfeitas através do compromisso de permanecerem juntos" (Sarason apud McMillan e Chavis, 1986, p. 9).

Este sentimento de comunidade é uma base importante neste contexto para promover bons encontros. Espinosa (1973) fala da paixão que leva os homens a se encontrarem, pois é através do outro que eles se descobrem a si mesmos. Consideramos que os bons encontros, por sua vez, revelam a potência de ação do ACS nesta relação entre ESF e a comunidade. Espinosa abarca a afetividade como elemento importante no processo de emancipação do sujeito, sugerindo que, na relação intersubjetiva, os aspectos ligados à necessidade, aos valores éticos, assim como a satisfação ficam mais salientes:

O grupo composto por docentes e discentes apresentou a proposta de mapeamento do território e de identificação dos munícipes que tenham alguma aproximação com o uso de ervas, seja sabendo utilizá-las ou até mesmo de tê-las plantadas em casa (Relato de 07.02.11.).

o grupo se dividiu para reencontrar uma munícipe, que já tinha demonstrado muito interesse em compor o grupo que pretende fazer uma horta comunitária. Na visita à casa desta munícipe, ela nos mostrou as plantas que possui em seu quintal [...] (Relato de 21.02.11).

Uma outra munícipe é uma benzedeira que não realiza o plantio de ervas, mas surgiu como uma possibilidade de conhecimento sobre ervas. Estas munícipes surgiram como pessoas com grande potencial para ajudar a compor a proposta, já que possivelmente detêm conhecimento sobre o uso de ervas (Relato de 14.02.11).

Do ponto de vista do processo e organização do trabalho, a relação com a comunidade revela aspectos da complexidade da função e do lugar de 
mediação que os ACSs ocupam. Eles referiram que se sentiam muito solicitados, destacando a falta de respeito aos limites da função:

Elas salientaram que essa profissão é muita desvalorizada pela população que utiliza da boa vontade delas para pedir assistência e também pelo Estado (ESF) do qual recebem um salário abaixo do devido e reduzido para o tanto de atribuições cabidas (Relato de 06.12.11).

As reclamações de falta de limites dos munícipes expressa uma ordem política-institucional complexa que contribuem para ambiguidades e conhecimento incipiente do papel da ESF e consequentemente da função dos ACSs. A relação empregatícia dos ACSs com a Secretaria Municipal de Saúde é mediada por uma Organização não governamental, pela qual os ACSs são contratados e pagos. Apesar da Lei n. 11.350/o6 que prevê a contratação formal do ACS (Lacerda, 2010). Especificamente esta situação da contratação gera ambiguidades e fragilidades sobre a sua legitimidade enquanto um trabalhador importante da saúde:

[...] A. disse que está bastante incomodada com o trabalho, pois ela comenta quenunca tem resposta pra nada, diz que há tempos está perguntando à chefia sobre alguns benefícios que já teriam que ter recebido e não tem uma resposta clara (Relato de 21.03.11).

A dimensão psicossocial e afetiva retrata a qualidade dos vínculos estabelecidos no cotidiano dos ACSs, contribuindo para a compreensão de uma dinâmica institucional contextualizada pelo processo de trabalho baseada no modelo capitalista (Rodrigues, 2005). A divisão técnica e social do trabalho coloca cada profissional em uma etapa do processo de produção, fazendo com que a tarefa seja realizada, mas perdendo de vista a finalidade do trabalho. No trabalho em saúde, ocorre também essa divisão em que uns prescrevem, outros supervisionam e outros ainda são os que aplicam (Ceccim e Merhy, 2009).

No caso dos ACSs, há uma valorização do cumprimento da cota mensal de visitas, ofuscando a tônica de um trabalho que se dá principalmente pela qualidade das interações humanas. Fortalecendo principalmente a capacidade de realização de um trabalho em equipe e a formação de uma rede entre os profissionais (Lacerda, 2010).

Além disso, o papel dos ACSs é enviesado por tarefas administrativas que reforçam o papel tarefeiro. De acordo com Nascimento e Correa (2008), a falta de esclarecimento pela equipe sobre as funções dos ACSs pode ser considerada um dos motivos pelos quais estes profissionais tenham sobrecarga de trabalho, visto que os outros integrantes da equipe da ESF consideram o ACS o "faz tudo", fazendo solicitações fora das atribuições destes. Dessa forma, os trabalhadores produzem e reproduzem-se em meio à separação entre satisfação e trabalho ou entre trabalho e criação, em que sua atividade torna-se cada vez mais um fardo e o trabalhar fica fora da vida.

Propõe-se, por outra via, um trabalho em equipe valorizando a interação do usuário com o trabalhador, a análise das disputas de poder e estabelecimento de projetos coletivos de cuidar, e da mesma forma "a equipe precisa ser cuidada para produzir cuidados" (Fortuna, 2003).

A insatisfação e exacerbação das solicitações desencadearam conversas com os ACSs sobre novos projetos de vida, muitas vezes pelo desejo de mudança de atividade profissional, aliás o desejo de procurar outro trabalho era corriqueiro. Buscar novos projetos de vida, especialmente no âmbito do trabalho revela que o ser humano é essencialmente social. Segundo Carreteiro (2006), com base no filósofo francês J. P. Sartre, esta essência produz ideais, desejos mobilizadores da transcendência que constantemente vão dirigi-lo para o futuro

participar de projetos, imaginá-los, sonhá-los, realizá-los, elaborá-los, destruí-los, abandoná-los representa laborar na construção da civilização. Porém, tal participação é experimentada diferentemente pelos sujeitos (individual ou coletivo), pois ela inclui elementos do lugar social ocupado pelos mesmos. Toda participação evoca um sujeito em situação, sendo sua conduta e escolhas reveladoras de sua maneira de estar sendo (Carreteiro, 2006, p. 91).

Nesta perspectiva exercer esta função de ACS possibilita o redimensionamento da rotina de vida, valendo-se de pequenas vantagens como a flexibilização de horários e proximidade do local de moradia, facilitando que, principalmente, as mulheres pudessem dar mais atenção aos filhos e 
ainda reforçar a renda familiar. Indicando que a função de ACS simboliza a possibilidade de ascensão social, movimentando outras dimensões da vida destes profissionais.

Tanto M. como A. relataram que quando conseguirem outro emprego bom se despedirão da função de agente. (Relato, o6.12.11).

Nesta perspectiva dos significados da relação com a função de ACS, percebemos que este novo status quo da pessoa que passa a ser ACS expressa a potencialização de recursos simbólicos presentes na comunidade, que em uma perspectiva crítica do conceito de capital social (Bourdieu, 1974) refere que este não é somente como um ganho individual, mas que do ponto de vista de crítica, o capital cresce por causa da acumulação e do uso, na perspectiva sociopolítica, visto que as relações de troca e confiança entre as pessoas possibilitam o crescimento deste capital social (Milani, 2003).

Todavia percebemos que o compartilhamento deste capital social acumulado em prol do fortalecimento comunitário é ofuscado por sentimentos de desqualificação dos ACSs em relação aos munícipes, rotulando os munícipes de preguiçosos e aproveitadores. Por exemplo, os ACSs destacaram que aproveitam ao máximo as poucas oportunidades dadas para sua qualificação, enquanto os munícipes recebem benefícios do governo, como cursos vinculados aos programas de transferência de renda e não aproveitam.

Consideramos que a desqualificação dos munícipes, seus vizinhos, por exemplo, expressa mecanismos psicológicos que sustentam a exclusão social reforçando atitudes preconceituosas. "Os estereótipos de deslegitimação visam excluir moralmente um grupo do campo das normas e de valores aceitáveis, por uma desumanização que autoriza a expressão do desprezo e do medo e justifica as violências e penas que lhe infligimos" (Jodelet, 2006, p. 64).

Os encontros com os ACSs exigia uma escuta sensível a estas imbricações entre o exercício da atividade profissional e questões pessoais, abarcando momentos de desabafo e expressão de angústia. Estas situações abriam portas para se questionar as demandas de psicoterapia individual, as quais partiam do próprio ACS, pois consideramos que a dimensão psicológica está imbricada com o contexto social, inclusive produzindo situações geradoras de sofrimento (Sawaia, 2002). Desta forma o trabalho psicológico deve buscar incrementar processos de conscientização, supondo que:

o ser humano transforma-se ao modificar sua realidade. Trata-se, por conseguinte, de um processo dialético, um processo ativo [...], que acontece somente através do diálogo. Esta consciência critica ante a realidade circundante e ante os outros traz assim a possibilidade de uma nova práxis, que por sua vez, possibilita novas formas de consciência. $\mathrm{O}$ novo saber da pessoa sobre sua realidade circundante a leva a um novo saber sobre si mesma e sobre sua identidade social (Martin-Baró, 1997, p. 16):

M. começou a chorar, e não conseguia mais falar, explicou que estava triste porque sabia que a mãe também estava triste no lugarnovo onde estava morando... disse que seu sobrinho está envolvido com drogas e que está dando muito trabalho, mas que ela tem fé que ele vai sair dessa (Relato de 18.10.10.).

As propostas dos encontros na Universidade eram planejadas após várias conversas ou momentos em que pudéssemos captar seus interesses e demandas. Nestas conversas se buscava a construção coletiva das atividades em que cada um pudesse dar sua contribuição singular. 0 que permeou todas as atividades ocorridas no Laboratório de Técnica Dietética foi o "fazer junto" e a construção de um espaço de troca de informações e saberes que tinham como mote a comida, o comer, a nutrição.

Percebemos que o fortalecimento psicológico pode ser compreendido como um processo pelo qual o sujeito desenvolve, juntamente com seus pares, capacidades e recursos para lidar com a própria vida, atuando de maneira comprometida, consciente e crítica, transformando a si mesmo e ao meio social em que vive (Montero, 2003). Desta forma alguns espaços públicos, baseados em princípios de cidadania, podem promover bons encontros, os quais favorecem a potencialização dos sujeitos em seu meio social (Sawaia, 2002):

Logo que os ACSs chegaram à universidade estavam bastante eufóricos e contentes de estarem ali, para que também possam sair do local de trabalho cotidiano e respirar "novos ares" (Relato de 25.10.10). 
Os alunos de nutrição prepararam para esse dia, para complementar o tema que está sendo abordado sobre as ervas com propriedades medicinais, receitas que envolvessem estas, mas que a preparação destas receitas tivesse mais um caráter lúdico, que fosse para as ACSs algo terapêutico, uma atividade que as fizessem descontrair. [...] Os alunos do curso de nutrição prepararam um folhetinho com as receitas, com fotos de folhas das ervas com propriedades medicinais (boldo, hortelã, etc). As ACSs estavam bem animadas; durante a preparação das receitas, a ACS M. deu algumas dicas (Relato de 21.03.11).

Nesta perspectiva a construção de estratégias pautadas no diálogo e interesses dos ACSs promove uma participação mais ativa do ACS em relação a sua prática cotidiana, por exemplo, sobre a dificuldade de lidarem com munícipes portadores de doenças crônicas. Segundo Montero (2003), considerar também a dimensão psicossocial permite pensar em níveis de fortalecimento.

Em seu próprio estudo, Zimmerman e Rappaport (1998) chegam à conclusão de que a participação em atividades e grupos comunitários é muito importante para compreender o conceito de fortalecimento e descrevem o fortalecimento psicológico como "a conexão" entre um sentido de competência pessoal e desejo e a vontade de atuar no espaço público (Montero, 2003, p. 72 grifo da autora).

A ACS comenta que muitas vezes sabe que os munícipes são hipertensos e diabéticos, mas que não aceitam a doença e quando faz a visita domiciliar na casa dessas pessoas muitos falam que não têm nenhum problema de saúde [...].

O aluno M., do curso de nutrição, inicia uma conversa a respeito da parte teórica sobre diabetes, $e$ as ACSs ficaram bastante interessadas (Relato de 09.05.11).

Segundo recomendações do Ministério da Saúde (Brasil 2005a, 2005b), questões de saúde devem ser problematizadas, destacando os dilemas vividos pelos profissionais dessa área, quanto às suas dificuldades em lidar com o paciente e com o contexto adverso em que está inserido, explicitando os dilemas de trabalhar em equipe e estabelecer um diálogo entre equipe e pacientes, entre equipe e familiares ou ainda entre profissional e paciente. Além disso, amplia-se o olhar sobre o paciente, considerando não apenas a patologia que este apresenta, mas valorizando a escuta, os afetos, anseios e esclarecimentos que a pessoa traz junto com suas dores e necessidades.

Nas etapas finais do projeto de extensão, impressionou a maneira segura e orgulhosa que os ACSs se expressaram dialogando com outros especialistas (residentes multiprofissionais e docentes) o saber sobre as plantas, inclusive participaram ativamente da confecção de uma cartilha de orientação sobre os prós e contras do uso de plantas, destacando opiniões sobre a linguagem mais apropriada à compreensão dos munícipes do conteúdo da cartilha. Este processo em que percebemos uma participação cada vez mais ativa do ACS reforça a proposta de fortalecimento comunitário como uma das principais estratégias de transformação das comunidades, visando melhorar a capacidade de cada um de controlar suas próprias vidas (Montero, 2003; Jariego, 2004; Carvalho, 2004). Entretanto, há sentidos múltiplos de se expressar esse fortalecimento, expresso inclusive na diversificação de terminologias referidas ao termo, sendo a mais conhecida o empowerment. Há tentativas de tradução dessa palavra para o português, como empoderamento, mas não existe este termo em nosso vocabulário. Em castelhano se diz empoderamiento e potenciación que, segundo Montero (2003), são usados, antes do termo em inglês, na Psicologia Comunitária por Rappaport (apud Montero, 2003).

Em se tratando da América Latina, a opção pelo termo fortalecimento significa que a emancipação dos sujeitos está associada com uma construção coletiva e democrática de uma sociedade mais justa, em que os sujeitos e as comunidades são ativos neste processo. Neste sentido o fortalecimento comunitário deve ser visto como um processo que implica níveis de fortalecimento individual, organizacional e comunitário. A noção de processo é fundamental, porque revela que contextos diferentes e singularidades dos indivíduos e dos grupos geram estratégias e expectativas diferentes (Castro e Silva, 2009):

Conforme ele (profissional da saúde) falava pra nós sobre tudo o que conhecia, as ACSs souberam identificar várias das ervas citadas e ainda contavam histórias sobre contatos que tiveram com algumas das citadas (Relato de 13.12.10). 
A ACS até pegou um papel e começou a reescrever uma frase do texto que disse estar confusa e que naquele formato os munícipes não entenderiam (Relato de 16.05.11).

A avaliação aconteceu durante o processo, principalmente em momentos de conclusão dos módulos ao longo de dois anos de atividades. Entretanto era algo presente e aceito em qualquer momento do processo, visto como um momento de construção de atividades dialogadas e interativas entre equipe-UNIFESP e ACS. A participação não é algo fácil de construir, principalmente na perspectiva da avaliação como nos lembra Furtado (2012), pois é necessário deixar de lado certa ingenuidade, primeiro de que participar implique em uma uniformização. Isto não acontece e é não recomendado do ponto de vista da promoção dos direitos, visto que estaríamos ignorando as diferenças e dissensos.

Do ponto de vista da proposta de extensão, alguns aspectos se mostraram presentes: primeiro o esforço de valorização das diferenças, expressadas pela subjetividade do ACS, aspecto importante para que se construam ações emancipadoras; segundo, que o desejo de participação é diferente, pois entre os ACSs notamos graus distintos de interesse pelo trabalho da extensão, havendo inclusive desistências tácitas sem abertura para o diálogo; terceiro, de que processos avaliativos inclusivos e participativos sejam simples. Isto significou que a efetivação da proposta de extensão era difícil de concretizar, pois pairavam expectativas distintas, da gestão em nível central da Secretaria de Saúde, do ACS e da equipe da universidade. Cabe destacar que, nestes momentos de avaliação, se reforçava a motivação primeira da proposta da extensão, ou seja, de espaço de escuta e acolhimento. De certa forma revelando a dinamicidade do cotidiano de trabalho e a necessidade de ressignificação constante de suas experiências:

[...] M. que diz que gosta muito do tema das ervas medicinais, mas que está sentindo falta de um espaço para discutir os problemas do seu dia a dia no trabalho; disse que queria atividades que envolvessem a psicologia, que estas atividades a ajudassem a lidar melhor com a cobrança dos munícipes, a sobrecarga do trabalho entre outros problemas (Relato de 21.03.11). Tanto a M. como a A. elogiaram o projeto e identificam melhoras no seu trabalho e reconhecem que de alguma forma o projeto funciona como um momento para serem cuidadas (Relato de o6.12.10).

\section{Considerações finais}

O ACS opera, fundamentalmente, naquilo que, na área da saúde, chamamos de campo psicossocial que, conforme Aranha e Silva e Fonseca (2005) tem como pressupostos: o planejamento do modelo assistencial coletivizado, produzido no espaço multiprofissional com qualidade interdisciplinar; a superação da rigidez da especificidade profissional; e a flexibilidade para produzir condições de saúde compatíveis com a necessidade do munícipe. Esta posição é coerente com a reorientação do modelo de atenção que concebe a saúde como processo e não como ausência de doença, na perspectiva de produção de qualidade de vida, enfatizando ações integrais e de promoção da saúde.

Para atender aos pressupostos do campo psicossocial, os instrumentos de intervenção devem adaptar-se à dinamicidade e flexibilidade das necessidades de saúde. Por isso a organização do trabalho deve ser o principal instrumento de produção de ações de saúde, a partir do qual os agentes podem experimentar novas tecnologias, testá-las e produzi-las, dispensá-las ou recuperá-las. Ou seja, o serviço deve ser o lugar de exercício da práxis, onde o saber origina-se da realidade concreta e a ela transforma, e, transformando a própria realidade, necessitará de novo transformar-se, em constante relação com a realidade. É inegável, portanto, o papel crucial desenvolvido pelos ACSs.

A “ação dos agentes de saúde, quando operada em singular parceria com os outros membros da organização sanitária, torna esta relação uma arma fundamental para fazer funcionar esta máquina de produzir saúde" (Lancetti, 20o6, p. 93). E se o fazem, continua o autor, é porque sua potencialidade está radicada nesta "condição paradoxal", qual seja, a “de viverem na alma da periferia”, portanto na comunidade onde atuam, e serem ao mesmo tempo da organização sanitária.

Neste sentido, a potencialização da capacidade de ação dos ACSs suscita a elaboração dos dilemas e dificuldades atuais enfrentados cotidianamente em suas práticas nas comunidades. Não só como 
profissional habilitado em saúde pública, mas como pessoa que se depara com limites, contradições e históricos de vida pessoais e coletivos com diferentes formas de sofrimento.

Trazer alguns flashes desta experiência de extensão universitária sugere a revelação de um processo em construção de vários tipos de inter-relacionamentos que têm como base a troca de experiências e saberes de atores que atuam em um mesmo território. Isto é, entre instituições que buscam se aproximar (Universidade e Serviço Público); de profissionais que buscam se reconhecer em atuação num mesmo campo (fortalecimento de ações do SUS); em suma entre aqueles que vivem nos Morros e aqueles que habitam a Orla, refletindo a luta contra a desigualdade social que ainda marca a nação brasileira.

\section{Referências}

ARANHA E SILVA, A. L.; FONSECA, R. M. G. S. Processo de trabalho em saúde mental e o campo psicossocial. Revista Latino-Americana de Enfermagem, Ribeirão Preto, v. 13, n. 3, p. 441-449, 2005.

BOURDIEU, P. A condição de classe e posição de classe. In: MICELI, S. (Org.). A economia das trocas simbólicas. São Paulo: Perspectiva, 1974. p. $63-85$.

BRASIL. Lei n ${ }^{0} 10.507$, de 10 de Julho de 2002. Dispõe sobre a criação da profissão de Agente Comunitário de Saúde e dá outras providências. Diário Oficial da República Federativa do Brasil, Brasília, DF, 11 jul. 2002. Disponível em: <http:// legis.senado.gov.br/legislacao/ListaPublicacoes. action?id=235057>. Acesso em: 20 fev. 2014.

BRASIL. Ministério da Saúde; Ministério da Educação. Referencial curricular para curso técnico de agente comunitário de saúde: área profissional saúde. Brasília, DF, 2004.

BRASIL. Ministério da Saúde. Secretaria de Gestão do Trabalho e da Educação na Saúde. Departamento de Gestão da Educação na Saúde. Curso de formação de facilitadores de educação permanente em saúde: unidade de aprendizagem: análise do contexto da gestão e das práticas de saúde. Rio de Janeiro, 2005a.
BRASIL. Ministério da Saúde. Secretaria de Gestão do Trabalho e da Educação na Saúde. Departamento de Gestão da Educação na Saúde. Curso de formação de facilitadores de educação permanente em saúde: unidade de aprendizagem: trabalho e relações na produção do cuidado em saúde. Rio de Janeiro, 2005b.

BRASIL. Lei ${ }^{0}$. 11.350, de 5 de outubro de 2006. Regulamenta o $\S 5^{\circ}$ do art. 198 da Constituição, dispõe sobre o aproveitamento de pessoal amparado pelo parágrafo único do art. $2^{\circ} \mathrm{da}$ Emenda Constitucional ${ }^{\circ}$ 51, de 14 de fevereiro de 2006, e dá outras providências. Diário Oficial da República Federativa do Brasil, Brasília, DF, 6 out. 2006. Disponível em: <http://portal.saude.gov.br/ portal/arquivos/pdf/lei1135o.pdf >. Acesso em: 7 abr. 2013.

CARRETEIRO, T. A doença como projeto: uma contribuição à análise de formas de filiações e desfiliações sociais. In: SAWAIA, B. As artimanhas da exclusão social: analise psicossocial e ética da desigualdade social. Petrópolis: Vozes, 2006. p. 87-96.

CARVALHO, S. Os múltiplos sentidos da categoria "empowerment" no projeto de promoção à saúde. Cadernos de Saúde Pública, Rio de Janeiro, v. 20, n. 4, p.1088-1095, 2004.

CASTRO E SILVA, C. R. A amizade e a politização de redes sociais de suporte: reflexões com base em estudo de ONG/Aids na grande São Paulo. Saúde e Sociedade, São Paulo, v. 18, n. 4, p. 721-732, 2009.

CECCIM, R. B.; MERHY, E. E. Um agir micropolítico e pedagógico intenso: a humanização entre laços e perspectivas. Interface: Comunicação, Saúde e Educação, Botucatu, v. 13, p. 531-542, 2009. Suplemento 1.

CHARMAZ, K. A construção da teoria fundamentada: guia prático para análise qualitativa. Porto Alegre: Artmed, 2009.

ESPINOSA, B. Ética. São Paulo: Abril Cultural, 1973. (Os Pensadores).

FERREIRA, V. S. C. et al. Processo de trabalho do agente comunitário de saúde e a reestruturação produtiva. Cadernos de Saúde Pública, Rio de Janeiro, v. 25, n. 4, p. 898-906, 2009. 
FORTUNA, C. M. Cuidando de quem cuida: notas cartográficas de uma intervenção institucional na montagem de uma equipe de saúde como engenhoca-mutante para produção da vida. 2003. Tese (Doutorado em Enfermagem de Saúde Pública) - Escola de Enfermagem de Ribeirão Preto da Universidade de São Paulo, Ribeirão Preto, 2003.

FURTADO, J. P. Avaliação e participação. In: BRANDÃO, D.; MARTINA, R. O. (Org.). Avaliação de programas e projetos: temas brasileiros. São Paulo: Peirópolis, 2012. p. 21-41.

GLASER, B. G.; STRAUSS, A. The discovery of grounded theory: strategies for qualitative research. Chicago: Aldine, 1967.

GOMES, K. O. et al. O agente comunitário de saúde e a consolidação do Sistema Único de Saúde: reflexões contemporâneas. Physis: Revista de Saúde Coletiva, Rio de Janeiro, v. 20, n. 4, p. 11431164, 2010.

JARDIM, T. A.; LANCMAN, S. Aspectos subjetivos do morar e trabalhar na mesma comunidade: a realidade vivenciada pelo agente comunitário de saúde. Interface: Comunicação, Saúde e Educação, v. 13, n. 28, p. 123-135, 2009.

JARIEGO, I. M. Sentido de comunidad y potenciación comunitaria. Apuntes de Psicología, Sevilla, v. 22, n. 2, p. 187-211, 2004.

JODELET, D. Os processos psicossociais da exclusão. In: SAWAIA, B. As artimanhas da exclusão social: análise psicossocial e ética da desigualdade social. Petrópolis: Vozes, 2006. p. 53-66.

LACERDA, A. Redes de apoio social no Sistema da Dádiva: um olhar sobre a integralidade do cuidado no cotidiano de trabalho do agente comunitário de saúde. 2010. Tese (Doutorado em Saúde Pública) - Fundação Oswaldo Cruz - Escola Nacional de Saúde Pública Sergio Arouca, Rio de Janeiro, 2010.

LANCETTI, A. A potência terapêutica dos agentes de saúde. In: . Clínica peripatética. São Paulo: Hucitec, 2006. p. 87-96.

McMILLAN, D.; CHAVIS, D. Sense of community: definition and theory. Journal of Community Psychology, New York, v. 14, p. 6-13, 1986.
MARTIN-BARÓ, I. O papel do psicólogo. Estudos de Psicologia, Natal, v. 2, n. 1, p. 7-27, 1997.

MILANI, C. Teorias do capital social e desenvolvimento local: lições a partir da experiência de Pintadas (Bahia-Brasil). In: CONFERÊNCIA REGIONAL ISTR-LAC, 4., 2003, San José. Caderno de resumos... Baltimore: ISTR, 2003. p. 1-30.

MONTERO, M. Teoria y práctica de la psicologia comunitária: la tensión entre comunidad y sociedad. Buenos Aires: Piadós, 2003.

NASCIMENTO, E. P. L.; CORREA, C. R. S. O agente comunitário de saúde: formação, inserção e práticas. Cadernos de Saúde Pública, Rio de Janeiro, v. 24, n. 6, p. 1304-1313, 2008.

NUNES, M. O. et al. 0 agente comunitário de saúde: construção da identidade desse personagem híbrido e polifônico. Cadernos de Saúde Pública, Rio de Janeiro, v. 18, n. 6, p. 16391646, 2002.

PASCHE, D. F.; PASSOS, E.; HENNINGTON, E. A. Cinco anos da política nacional de humanização: trajetória de uma política pública. Ciência \& Saúde Coletiva, Rio de Janeiro, v. 16, n. 11, p. 45414548, 2011.

RAMOS, T. Formação técnica e desprecarização dos ACS: uma luta por cidadania. Rio de Janeiro: Fiocruz, 2007.1 CD. Aula inaugural - Escola Politécnica de Saúde Joaquim Venâncio.

RODRIGUES, A. Indivíduo, grupo e sociedade: estudos de psicologia social. São Paulo: EdUSP, 2005 .

SANTOS, M. R.; PIERANTONI, C. R.; SILVA, L. L. Agentes comunitários de saúde: experiências e modelos do Brasil. Physis: Revista de Saúde Coletiva, Rio de Janeiro, v. 20, n. 4, p. 1165-1181, 2010.

SANTOS, K. T. et al. Agente comunitário de saúde: perfil adequado a realidade do Programa Saúde da Família? Ciência \& Saúde Coletiva, Rio de Janeiro, v. 16, p. 1023-1028, 2011. Suplemento 1. 
SAWAIA, B. O sofrimento ético-político como categoria de análise da dialética exclusão/ inclusão. In: SAWAIA, B. (Org.). As artimanhas da exclusão: uma análise ético-psicossocial. 4. ed. São Paulo: Vozes, 2002. p. 97-118.

UNIFESP - UNIVERSIDADE FEDERAL DE SÃO

PAULO. Campus Baixada Santista. Projeto

Político Pedagógico. Santos, 2006. Disponível em: <http://www.baixadasantista.unifesp.br/ projetopedagogico_baixada.pdf $>$. Acesso em: 22 maio 2012. 